\title{
A oralidade no processo penal a partir da noção de compreensão cênica
}

\author{
The orality in criminal procedure from the \\ notion of scenic understanding
}

Gabriel Rodrigues de Carvalho ${ }^{\mathbf{1}}$

Curitiba/PR

gabrielr.carvalho@hotmail.com

lattes.cnpq.br/8149909252328266

orcid.org/0000-0002-3648-011X

Resumo: O presente trabalho visa a analisar a textualização do processo penal, para verificar como a ela se contrapõe a oralidade, através da noção de compreensão cênica, construída por Winfried Hassemer e Alfred Lorenzer, constatando quais são as suas vantagens em face da compreensão textual. Após, buscar-se-á apurar qual são os efeitos que essas vantagens ocasionam tanto para o princípio do contraditório, quanto para o princípio do dispositivo, reafirmando o processo penal como eminentemente acusatório.

Palavras-chave: Processo Penal; compreensão cênica; oralidade; contraditório; sistema acusatório.

ABSTRACT: The present work aims to analyze the textualization of the criminal procedure, to verify how it is opposed to orality, through the notion of scenic understanding (from Winfried Hassemer e Alfred Lorenzer), noting its benefits in the face of textual understanding. Afterwards, it will seek to investigate the effects of these benefits on the principle of contradictory, reaffirming the criminal procedure as eminently accusatory.

KEYwoRDs: Criminal Procedure; Scenic Understanding; Orality; Contradictory; Accusatory System.

1 Pós-graduado em Direito Penal e Processual Penal pelo Centro Universitário Curitiba (2015). Graduado em Direito pelo Centro Universitário Franciscano do Paraná (2013). Advogado criminalista (OAB/PR). 
SUMÁRIO: Introdução; 1. A compreensão textual como oposição à oralidade; 2. A compreensão cênica; 2.1 A compreensão cênica de Alfred Lorenzer; 2.2 O entendimento de Hassemer e a respeito da compreensão cênica no processo penal; 3. A compreensão cênica e o contraditório de um processo penal acusatório; 3.1 Valorização do contraditório como garantia de um sistema acusatório; Considerações finais; Referências

\section{INTRODUÇÃO}

Acredita-se não haver mais dúvidas de que, quando o assunto é o Direito processual penal, é necessário caminhar "nos labirintos da linguagem"2. Numa práxis tão predominantemente escrita, mas que parece não conseguir dar efetividade aos objetivos democráticos da Constituição de 1988, questionar qual é essa linguagem, e como ela atua na prática, não parece ser um questionamento vazio de importância.

Por essa razão é que a oralidade será o tema central do presente (e bastante breve) ensaio, em especial por se contrapor, como se demonstrará, à uma compreensão textual ainda muito arraigada na prática jurídica.

Elege-se, para a investigação proposta, uma análise da noção de compreensão cênica, trazida para o processo penal por Winfried Hassemer, com base nos estudos de Alfred Lorenzer, justamente porque tal compreensão, nos termos elaborados por ambos os autores, parece não apenas aduzir a importância da oralidade, mas também construir um entendimento processual que respeite a importância da atuação das partes, os limites do julgador (como ser humano que é), e as regras de um jogo democrático.

Para tanto, será realizado um contraponto entre escrita e oralidade, para que, em seguida, seja possível analisar a noção de compreensão cênica e, ao final, averiguar quais são algumas das possíveis van-

2 COUTINHO, Jacinto Nelson de Miranda. Sistema acusatório: cada parte no lugar constitucionalmente demarcado. Revista de Informação Legislativa, v. 183, p. 103-115, 2009, p. 108. 
tagens que essa noção pode trazer para um processo penal pautado no contraditório, e regido por um sistema verdadeiramente acusatório.

\section{A COMPREENSÃo TEXTUAL COMO OPOSIÇÃo À ORALIDADE}

O cerne da presente pesquisa reside na "compreensão cênica", noção trabalhada por Winfried Hassemer, em sua obra "Introdução aos fundamentos do Direito Penal”. Antes de dissecar essa noção, porém, é possível dizer que o mencionado autor a contrapõe ao que denomina de “compreensão textual”, e o faz a partir da seguinte visão a respeito da hermenêutica:

A hermenêutica filosófica refletiu originalmente e em trajeto mais amplo, não a compreensão dos textos, mas a compreensão da vida, das etapas, dos processos, das situações. A hermenêutica jurídica, ao contrário, [...] há muito discute a compreensão dos textos. [...] A linguagem hermenêutica do "fato e da norma" compreende por "fato" um produto que entra em conflito com a norma. De modo contrário, o processo real em que se realiza este conflito ainda não foi abrangido por esta visão. A hermenêutica jurídica continua sendo uma teoria do direito material, uma teoria dos textos. ${ }^{3}$

A conclusão do autor a respeito desse raciocínio é de que o conceito de compreensão acaba por se mostrar limitado pela fixação à escri$\mathrm{ta}^{4}$. Hassemer, porém, não está sozinho em sua conclusão a respeito dessa "textualização do direito" ${ }^{5}$, questão objeto dos mais diversos estudos ${ }^{6}$.

3 HASSEMER, Winfried. Introdução aos fundamentos do direito penal. Trad. Pablo Rodrigo Alflen da Silva. Porto Alegre: Sergio Antonio Fabris, 2005, p. 177.

4 HASSEMER, Winfried. Introdução aos fundamentos..., op. cit., p. 178.

5 BAZERMAN, Charles. Teoria da ação letrada. Trad.: Milton Camargo Mota, Angela Paiva Dionísio e Judith Hoffnagel. São Paulo: Parábola Editorial, 2015, p. 206.

6 Nesse sentido, cf.: "Textos escritos são ubíquos em nosso sistema legal. Advogados e juízes criam tais textos praticamente todos os dias, e quando eles não estão os redigindo, muitas vezes estão se esforçando para interpretá-los e aplicá-los. O Direito é, certamente, uma das profissões mais literais. Textos legais também são extremamente importantes para o resto da socie- 
Mais do que a teoria, a prática nos mostra, dia após dia, o quão textualizada é a práxis jurídica, em especial no processo penal; têm-se, a título de exemplo, as alterações que a Lei n ${ }^{0}$ 11.719/2008 efetuou no Código de Processo Penal (CPP) brasileiro. A referida legislação "desenhou um procedimento fundado na aglutinação de todos os atos de instrução numa mesma audiência"7.

Com o atual artigo 400 do CPP, assim, a regra seria a apresentação de alegações finais e a prolação de sentença de forma oral, o que, entretanto, é muitas vezes ignorado, seja por uma suposta "complexidade do caso" (art. 403, § $3^{\circ}$, do CPP), seja pelo simples costume, em que rotineiramente essa etapa é elaborada pelas partes via memoriais escritos, sem motivo pelo qual se opta pela exceção à atual regra.

Outro exemplo se encontra nos antigos 306 e 310, do Código de Processo Penal, que preveem a análise das prisões em flagrante, pelo Poder Judiciário, pelo mero recebimento do Auto de Prisão em Flagrante Delito (ADPF). Felizmente, ao menos nesse ponto, houve significativas mudanças a partir do exercício de um controle de convencionalidade ${ }^{8}$,

dade. Documentos como estatutos, opiniões judiciais, escrituras, testamentos e contratos literalmente governam muito de nossas vidas" (TIERSMA, Peter. Parchment, Paper, Pixels: Law and the Technologies of Communication. Chicago: University of Chicago Press, 2010. p. 1, tradução livre). Além de Bazerman e Tiersma, no Brasil, cf.: "A linguagem é o instrumento de trabalho do operador do Direito. Logo, o profissional da área jurídica deve dominar o seu instrumento de trabalho - a língua portuguesa, neste estudo especificamente, a modalidade escrita. Além dos conhecimentos gramaticais, é importante saber articular as palavras e materializar argumentos em um texto de forma coerente, além de ser capaz de transmitir a mensagem ao receptor de forma clara e concisa". (VIANA, Daniel Roepke; ANDRADE, Valdeciliana S. R. Direito e Linguagem: os entraves linguísticos e sua repercussão no texto jurídico processual. Revista de Direitos e Garantias Fundamentais, Vitória, n. 5, p. 37-60, jan./jun. 2009, p. 38).

7 LOPES JR., Aury. Direito processual..., op. cit., p. 960.

8 Trata-se da atenção ao art. 7.5 da Convenção Americana de Direitos Humanos, da qual o Brasil é signatário. Tal controle, até o momento, não se deu por via legislativa, mas sim através de uma iniciativa do Conselho Nacional de Justiça, em especial por meio da Resolução ${ }^{\circ}$ 213, de 15/12/2015, além de diversas resoluções específicas dos Tribunais de Justiça Estaduais. Sobre a convencionalidade das audiências de custódia, os regramentos existentes, e os projetos de lei nesse sentido, cf.: PAIVA, Caio. Audiência de custódia e o processo penal brasileiro. Florianópolis: Empório do Direito, 2015. 
adotando-se as chamadas audiências de custódia em grande parte do país. Com elas, as decisões a respeito das prisões cautelares passaram a não apenas ocorrer oralmente, mas também dentro de seu contexto específico, e com a respectiva oitiva do custodiado.

Caio Paiva é preciso ao definir que a implementação das audiências de custódia abandona um "sistema puramente cartorial, em que o Poder Judiciário, de forma asséptica, decide a partir do papel, sem garantir ao preso o direito de - pessoalmente - se fazer ouvir" ${ }^{\text {, }}$ método decisório esse que se tornou um verdadeiro comportamento padronizado e burocrático.

Essa recente alteração na prática penal demonstra que, de fato, a textualização do direito traz em si consideráveis consequências, normalmente ignoradas pelos operadores e estudiosos do Direito. Visando averiguar as verdadeiras características do texto escrito - e de suas diferenças em relação à palavra enunciada - interessante se mostra o estudo elaborado por Charles Bazerman, da Universidade da Califórnia (EUA), o qual parte de um conceito de escrita assim elaborado:

Apresentei a escrita como uma forma de atividade social, mediada, aprendida, realizada à distância. A escrita opera por meios cognitivos que alinham escritor e leitor com locais de intercâmbio simbólico percebidos em comum e, em seguida, realizam interações específicas dentro de um espaço. Neste espaço, o escritor oferece representações, transformações e atos organizados temporal e espacialmente, buscando influenciar o estado cognitivo, a disposição e a organização mental dos leitores, que lhes dão atenção para interpretar, avaliar, responder, usar, esquecer, ou se lembrar deles com base em suas próprias posições, situações e interesses. ${ }^{10}$

Essa maneira como opera a escrita, para o mencionado autor, embora associado à fala ${ }^{11}$, com ela guarda significativas diferenças - e isso, no presente trabalho, é de fundamental importância. Afinal, o que Bazerman busca expor é que, apesar da grande importância da palavra escrita (e do

\footnotetext{
9 PAIVA, Caio. Audiência de custódia e..., op. cit., p. 56.

10 BAZERMAN, Charles. Teoria da ação..., op. cit., p. 13.

11 BAZERMAN, Charles. Teoria da ação..., op. cit., p. 23.
} 
letramento $)^{12}$, nela existem fragilidades não constatadas na interação da palavra enunciada, uma vez que a leitura/escrita constitui uma experiência semiprivada na qual "as pistas que os escritores oferecem aos leitores para reconstruir significados são mais escassas do que na interação face a face"13.

Outra dificuldade que a comunicação letrada encontra é a invisibilidade de uma característica própria da comunicação: sua fragilidade, a qual, na comunicação face a face, é dificilmente detectável, diante do constante ajuste elaborado pelos interlocutores para dar continuidade à comunicação, consertando eventuais rupturas ${ }^{14}$; em sentido oposto, na interação por meio da escrita, essas rupturas se dão "fora da vista" ${ }^{15}$. É nesse ponto que as diferenças entre a palavra escrita e a palavra enunciada se evidenciam, ficando claras, também, suas consequências, inclusive na área do Direito. Como afirma Bazerman, "não importa quão bem trabalhado seja um texto, ele é sempre poroso, mesmo na área do direito - razão ela qual temos advogados e tribunais"16.

Se advogados e tribunais, porém, atuarem presos à palavra escrita, é sua porosidade que prevalecerá, em detrimento da atuação desses (e de outros quaisquer) operadores do Direito. Afinal:

Enquanto a conversa face a face oferece muitos dispositivos para manter a interação, apesar de desalinhamentos transitórios e ameaças de rupturas, as interações letradas à distância têm atenção apenas para a palavra escrita, na produção e na recepção, como um mecanismo de mediação. [...] Mesmo com alto grau de comprometimento e habilidade em ambos os lados, o nível de coalinhamento e entendimento mútuo é, frequentemente, menor do que a fixidez do texto inscrito pode sugerir. ${ }^{17}$

12 "A linguagem facilitou a criação de culturas e sociedades locais, mas o letramento tornou possíveis as grandes estruturas da modernidade que distribuem conhecimento, orientação e atividades por distâncias maiores do que se pode imaginar, fomentando uma maior complexidade do comportamento, bem como uma maior coordenação para suportar essa complexidade" (BAZERMAN, Charles. Teoria da ação..., op. cit., p. 205).

BAZERMAN, Charles. Teoria da ação..., op. cit., p. 177.

14 BAZERMAN, Charles. Teoria da ação..., op. cit., p. 138.

15 Ibidem, idem.

16 Ibidem, idem.

17 BAZERMAN, Charles. Teoria da ação..., op. cit., p. 145. 
Surge, pois, o papel da retórica - que, para Bazerman, "busca articular fortes formas de ordem para guiar as pessoas na prática” ${ }^{18}$-, a qual, na palavra escrita, acaba por atuar com maior força:

Na retórica face a face, podemos ver, ouvir, e cheirar a situação e monitorar as reações das pessoas com quem estamos falando - até mesmo de formas que se encontram abaixo do pensamento consciente. O imediatismo, mesmo sem ferramentas reflexivas, pode levar-nos muito longe na fala adequada e na compreensão; no entanto, mesmo nessas condições face a face, a retórica oferece vantagem reflexiva. Em situações de escrita, nossa necessidade de retórica é tanto maior porque podemos ter pouca informação situacional imediata e ainda menos sensação visceral imediata, razão pela qual precisamos contar com nossa compreensão padronizada de como as situações se desenrolam, da organização de empreendimentos sociais, dos papéis e relações de participantes e dos interesses e normas do público. ${ }^{19}$

Se a escrita, ao contrário da oralidade, perde o imediatismo da informação situacional e da sensação visceral, precisando recorrer à compreensão padronizada, mais difícil é o compartilhamento de significados e o entendimento mútuo entre os interlocutores, o que impõe a análise de alternativas à compreensão textual e suas fragilidades.

\section{A COMPREENSÃO CÊNICA}

Como visto no início do presente trabalho, Hassemer defende a existência de uma limitação da compreensão fixada nos textos, o que, conforme o item anterior, não é uma conclusão carente de base concreta. Desta feita, o doutrinador alemão defende uma ampliação do conceito de compreensão que existe no processo penal, em atenção ao poder de compreensão exigido pela palavra pronunciada ${ }^{20}$, abrangendo

\footnotetext{
18 BAZERMAN, Charles. Teoria da ação..., op. cit., p. 125-126.

19 BAZERMAN, Charles. Teoria da ação..., op. cit., p. 126.

20 HASSEMER, Winfried. Introdução aos fundamentos..., op. cit., p. 178.
} 
"a dimensão do procedimento, o processo, a sequência dos atos, a cena"21; trata-se do que o autor denomina de compreensão cênica.

Antes de se adentrar a essas sugestões do doutrinador alemão, insta salientar que essa compreensão é por ele conceituada como "a recordação concreta de fases da própria vida" ${ }^{2}$, conceito esse oriundo dos estudos de Alfred Lorenzer na área da psicanálise, os quais merecem uma rápida análise.

\subsection{A COMPREENSÃo CÊNICA de Alfred LORENZER}

Cabe aqui um parêntese para uma (bastante breve) incursão nos estudos de Alfred Lorenzer - posteriormente utilizados por Hassemer para elaboração de suas propostas para o processo penal -, voltados a analisar a influência das condições sociais na estrutura subjetiva ${ }^{23}$, e nos quais o autor constrói a noção de compreensão cênica como um meio termo entre outras duas compreensões da psicanálise: a compreensão lógica (entendida como compreensão da fala) e a compreensão psicológica (como compreensão do falante, a partir do que denomina de "revivência") ${ }^{24}$.

Trata-se, em resumo, de outra maneira de se interpretar as representações do paciente submetido à psicanálise, colocando-o como ponto de referência para a interpretação dessas representações:

Por certo que essas representações se apreendem como proposições providas de sentido, e com ajuda da compreensão lógica. Porém, uma vez apreendidas, já não são interpretadas como produto de um sentido irreal, mas sim como descrição da respectiva individualidade, ligadas com a realidade vivencial do paciente. Com isso, alcançam aquela posição intermediaria que Rickert designou de 'realidade provida de sentido'. [...] É

21 Ibidem, idem.

22 Ibidem, idem.

23 SALLING OLESEN, Henning; WEBER, Kirsten: Socialization, language and scenic understanding: Alfred Lorenzer's contribution to a psycho-societal methodology. Historical Social Research, Berlin, v. 38, n. 2, 2013, p. 26-55, p. 29.

24 LORENZER, Alfred. El lenguaje destruido y la reconstrucción psicoanalítica Trabajos preliminares para una metateoría del psicoanálisis. Trad. Roberto Bein. Buenos Aires: Amorrortu, 1977, p. 123-124. 
um terceiro plano da compreensão, em que [...] se desenvolve a principal compreensão psicanalítica. ${ }^{25}$

Essa realidade provida de sentido, para a psicanálise, exterioriza-se a partir de vivências, de um ordenamento cênico que se refere ao paciente, e constitui o plano nuclear da psicanálise; em síntese, "o trabalho gira incessantemente ao redor dessas cenas" ${ }^{26}$. Com isso, Lorenzer conclui que a compreensão psicanalítica estaria centrada na compreensão da situação:

A compreensão da realidade provida de sentido equivale à capacidade de compreender a situação relacional dos sujeitos com seus objetos, e as interações entre os sujeitos. [...] O ‘sentido' não interessa a essa compreensão como algo objetivo, desprendido dos sujeitos; somente se apreende os processos com vistas à realização do sujeito em sua relação com a sociedade e com o meio, na realização do sujeito dentro de seu campo relacional. ${ }^{27}$

Lorenzer denomina essa compreensão de compreensão cênica, a qual não diria respeito apenas ao paciente, mas também ao psicanalista, cujo foco nas representações do paciente exigiria uma concentração nas cenas de interação ${ }^{28}$; nesse processo compreensivo, o sentido correto das comunicações se abriria apenas a posteriori ${ }^{29}$ :

A proposição singular não é explicitada desde uma regra teórica, não se submete a uma hipótese prefixada; somente se pode compreendê-la a partir de um nexo de sentido que se forma no transcurso do processo de compreensão, e desde o qual unicamente se faz possível a pergunta pelos significados, que é o que interessa no momento. [...] No transcurso da análise se afirma a certeza: a princípio, a cena pode significar muitas coisas, ao final, muitas menos. ${ }^{30}$

25 Ibidem, idem (tradução livre).

26 LORENZER, Alfred. El lenguaje destruido..., op. cit., p. 125 (tradução livre).

27 LORENZER, Alfred. El lenguaje destruido..., op. cit., p. 126 (tradução livre).

28 Ibidem, idem.

${ }^{29}$ LORENZER, Alfred. El lenguaje destruido..., op. cit., p. 131.

${ }^{30}$ Ibidem, idem (tradução livre). 
É justamente a partir dessa forma de construir um sentido que Hassemer importa a noção trabalhada por Lorenzer para o processo penal.

\subsection{HASSEMER E A COMPREENSÃO CÊNICA NO PROCESSO PENAL}

Com base na teoria da psicanálise acima mencionada, Hassemer defende uma ampliação da compreensão processual, como visto, a qual se daria "desde o caso produzido até a produção do caso"31. Aí reside sua aproximação com os estudos de Lorenzer: na construção gradativa de um sentido, o que seria mais coerente com o que, de fato, se constitui o processo penal: uma sequência de atos, que ocorrem de forma consecutiva, aliado à uma constante interação entre seus participantes, tudo seguindo um determinado padrão estabelecido pelo direito processual ${ }^{32}$.

A importância dessa sequência dos atos, para Hassemer, é que a "produção de todo caso depende não só de critérios de seleção corretos, mas depende também da sequência de condutas bem sucedidas"33. Daí o recurso aos estudos acima mencionados de Lorenzer:

O poder de compreensão e as condições de compreensão na compreensão cênica ultrapassam completamente as possibilidades de compreensão de texto, ele garante à psicanálise apenas a esperança na cura: não é a recordação cognitiva e emotiva da própria história, mas somente a representação de suas cenas que as tornam tão atuais e que podem ser trabalhadas. ${ }^{34}$

O autor, entretanto, deixa claro que não há semelhanças entre o processo psicanalítico em si e o Processo Penal (eis que existem grandes diferenças entre as relações dos participantes do processo e aqueles da situação analítica); o que aproxima a compreensão cênica do Direito processual penal é a tradição da teoria hermenêutica ${ }^{35}$ :

31 HASSEMER, Winfried. Introdução aos fundamentos..., op. cit., p. 178.

32 HASSEMER, Winfried. Introdução aos fundamentos..., op. cit., p. 179-180.

33 HASSEMER, Winfried. Introdução aos fundamentos..., op. cit., p. 173. Insta salientar que esses critérios de seleção corretos seriam oriundos do Direito penal material.

34 HASSEMER, Winfried. Introdução aos fundamentos..., op. cit., p. 178.

35 Ibidem, idem. 
Atrás dos textos estão os homens que os escreveram, mas que não estão mais à vista. Ao contrário, no falar mostra-se não só o homem falante, com gestos, mímicas e entonação; a palavra pronunciada - como o texto - não pode se afastar da situação em que é pronunciada e ouvida. Pode-se ver que a ligação entre a palavra e a situação relatada é tão estreita que a palavra co-determina a situação e que, por outro lado, pode se compreender a palavra a partir da situação. ${ }^{36}$

O processo penal é, pois, uma sequência de atos, dos quais se deve extrair uma compreensão que não pode se dar alheia a cada um desses atos e à sequência por eles elaborada, como ocorre nos casos limitados a uma compreensão eminentemente textual. É por essa razão que a assunção da oralidade, compreendida na noção de compreensão cênica, não é uma simples mudança de procedimento no processo penal, mas sim de sua estrutura.

\section{A COMPREENSÃO CÊNICA E O CONTRADITÓRIO DE UM PROCESSO PENAL ACUSATÓRIO}

Diante do que acima se verificou a respeito da compreensão textual, possível concluir que a prevalência da escrita sobre a oralidade majora as chances de que as decisões judiciais proferidas em um procedimento majoritariamente escrito recaiam em solipsismo. Afinal, como defendido por Bazerman (em passagem anteriormente já mencionada), ao contrário da oralidade, a escrita exige o recurso à "compreensão padronizada de como as situações se desenrolam, da organização de empreendimentos sociais, dos papéis e relações de participantes e dos interesses e normas do público" ${ }^{37}$.

Esse recurso, porém, não ocasiona um resultado oriundo de um procedimento em contraditório; ter-se-ia, em verdade, uma mera escolha, "um ato de opção que se desenvolve sempre que estamos diante de duas ou mais possibilidades, sem que isso comprometa algo maior do

36 HASSEMER, Winfried. Introdução aos fundamentos..., op. cit., p. 179.

37 BAZERMAN, Charles. Teoria da ação..., op. cit., p. 126. 
que o simples ato presentificado em uma dada circunstância. Em outras palavras, a escolha é sempre parcial" 38 .

Esse problema já fora bem trabalhado por Nilo Bairros de Brum, em 1980, ao constatar a utilização, pelos julgadores, de requisitos retóricos nas sentenças penais, visando a torna-las aceitas pela comunidade jurídica $^{39}$. Isso se daria porque, não raras vezes, quando da prolação da sentença penal, o julgador já teria tomado uma decisão a respeito de absolvição ou condenação, sem, necessariamente, fazê-lo de forma lógica ou condizente com os ditames legais (por influência dos antecedentes do réu, ou da gravidade do delito, por exemplo $)^{40}$.

Ciente o julgador que tais motivações não teriam a esperada e necessária aceitação sem uma "roupagem racional e tecnicamente legítima" ${ }^{41}$, resta-lhe recorrer a requisitos retóricos como disfarce, tudo "através da avaliação da prova ou por meio da interpretação da norma” ${ }^{42}$.

A aproximação entre os alertas de Brum, com as constatações feitas por Bazerman a respeito do texto escrito são, pois, evidentes, uma vez que "a linguagem escrita está muito mais profundamente vinculada ao discurso interior do que à linguagem falada" ${ }^{43}$, fazendo com que as palavras fiquem mais suscetíveis a interpretações e reconstruções eventualmente diversas do que intentava o escritor ${ }^{44}$.

$O$ resultado de um processo penal eminentemente escrito, portanto, pouco ou nada se sustentaria no contraditório, pois majora a possibilidade de que tal resultado se dê apenas sustentado em uma escolha (solipsismo) do julgador que, também na (e pela) escrita, poderá se disfarçar de requisitos retóricos que lhe dê aparência de legitimidade. Importante que se diga, inclusive, que isso não demonstra uma atuação

38 STRECK, Lenio Luiz; OLIVEIRA, Rafael Tomaz de. O que é isto - garantias processuais penais? Porto Alegre: Livraria do Advogado, 2012, p. 15-16.

39 BRUM, Nilo Bairros de. Requisitos retóricos da sentença penal. São Paulo: RT, 1980, p. 72.

40 Ibidem, idem.

41 Ibidem, idem.

42 BRUM, Nilo Bairros de. Requisitos retóricos..., op. cit., p. 73.

43 BAZERMAN, Charles. Teoria da ação..., op. cit., p. 68.

44 BAZERMAN, Charles. Teoria da ação..., op. cit., p. 178. 
intencional de alguns julgadores em decidir um caso penal alheio ao que, efetivamente, produziu-se a partir do contraditório. Afinal:

Após o acesso ao lugar de julgador, diante da dificuldade de julgamentos diários e repetitivos, ele cria mecanismos de facilitação do processo de tomada de decisão. [...] Com o tempo, diante da construção de padrões de decisão, o mecanismo reflexivo é tomado pela heurística. Estabelecem-se mecanismos intuitivos, à disposição, fixando padrões de decisão. Os juízes acostumam-se a formar mecanismos pelos quais se convencem de que algum sexto sentido os ajudará a decidir a questão, não fosse esse sexto sentido uma ilusão simplificadora da complexidade. Mas o hábito do cachimbo deixa, muitas vezes, a boca torta. ${ }^{45}$

Aqui também se verifica a compreensão padronizada mencionada por Bazerman, na forma de construção de padrões de decisão; a escrita aumenta, pois, a possibilidade de atuação das heurísticas ${ }^{46}$ (intuitivas). Essas heurísticas, para Daniel Kahneman, assim se exteriorizam: "quando confrontados com uma questão difícil, muitas vezes respondemos a uma mais fácil em lugar dela, normalmente sem perceber a substituição".

Enquanto for comum a atuação das heurísticas, por parte dos julgadores, quando da decisão judicial ${ }^{47}$, a busca pela "aten-

45 ROSA, A. M. Guia compacto do processo penal conforme a teoria dos jogos. 2. Ed. Rio de Janeiro: Lumen Juris, 2014, p. 79.

46 "A definição técnica de heurística é um procedimento simples que ajuda a encontrar respostas adequadas, ainda que geralmente imperfeitas, para perguntas difíceis. A palavra vem da mesma raiz que heureca" (KAHNEMAN, Daniel. Rápido e devagar: duas formas de pensar. Trad.: Cássio de Arantes Leite. Rio de Janeiro: Objetiva, 2012, p. 127).

47 Nessa toada, importa também aduzir os estudos de Bernd Schünemann, quem concluiu que "O juiz tem a tendência de perseverar na descrição do crime, relatada no inquérito policial. Além do mais, o magistrado não só menospreza informações dissonantes, como também, e com frequência, não as aceita nem uma só vez como verdadeiras, o que, segundo a Psicologia Cognitiva, explica-se pela apercepção favorita e pela retenção de informações redundantes" (SCHÜNEMANN, Bernd. O juiz como um terceiro manipulado no processo penal? Uma confirmação empírica dos efeitos perseverança e correspondência comportamental. Trad. José Danilo Tavares Lobato. Revista Liberdades, n. 11, p. 30-50, set./dez. 2012, p. 44). O referido trabalho é de importância reconhecida na área do processo penal, primordialmente por trazer impor- 
ção durante os subjogos probatórios" ${ }^{48}$ receberá demasiada importância ${ }^{49}$.

Essa constatação é importante para rechaçar a racionalidade perfeita e intocável do processo penal ${ }^{50}$, o que majora a importância de se rever alguns costumes processuais - como o conforto do texto escrito -, para que o resultado do jogo processual não resida apenas numa aleatória (e nem sempre racional) preferência por parte do julgador.

Afinal, se o texto escrito majora a incidência de heurísticas intuitivas, e se, no jogo processual, a busca pela atenção do julgador assume demasiada importância, então a assunção da oralidade teria um duplo efeito: não apenas diminuiria as decisões "fáceis" (nas palavras de Kahneman), numa inapropriada simplificação, como ainda aumentaria significativamente as possibilidades de prender a atenção

tantes teorias da psicologia cognitiva para o âmbito da decisão judicial, como a Teoria da Dissonância Cognitiva e a Teoria do Comportamento Social.

ROSA, A. M. Guia compacto do...op. cit., p. 84.

49 “...] por mais que a situação processual seja corriqueira, a atitude do julgador deve ser cativada. No caso do processo penal a liberdade e muitas vezes a vida do acusado está em jogo e, por isso, recomenda-se que se possa ser diligente às possibilidades de engano, tão comuns, aliás. Chamar a atenção do julgador sobre o que é importante exige uma tática elaborada” (Ibidem, idem).

A obra de Alexandre Morais da Rosa, aqui mencionada, tem justamente essa missão, diga-se. Nesse sentido, cf.: ROSA, A. M. Guia compacto do...op. cit., p. 85. “Talvez por aí se possa entender porque a mente humana não é tão racional e lógica como aparenta, mas sim sujeita a falhas de cognição. Entretanto, o mito construído pelo Direito é o da racionalidade. Esse Guia Compacto aceita a ideia de que a mente dos humanos e dos julgadores é suscetível a erros sistemáticos, muitas vezes sem se dar conta. Especialmente porque no processo penal o discurso lançado e que pretende confirmar a existência de uma conduta do mundo da vida é trazida por terceiros. Lembremos que o julgador é um terceiro que não sabe dos fatos. Logo, a incerteza do acontecido é ponto de partida e o risco de erros é uma variável não desprezável”. Nesse mesmo sentido, cf., ainda: "O controle, de fato, para nós, é uma quimera. Faz-se de conta que a subjetividade não existe, ou melhor, sua existência, quando admitida, encontra total controle no livre convencimento. O juiz, de regra, é apresentado como um robô, um ser transparente através do qual flui a "vontade" da lei; e alguns, falando sério, acreditam realmente que ela a detém. Ignorase, quase por completo, o homem, em um esforço incomum visando encalacrar nele - e em todos nós - a consciência de que sua função é espelhar uma vontade que não é sua”. In: COUTINHO, J. N. de. M. A lide e o conteúdo do processo penal. Curitiba: Juruá, 1989, p. 136. 
do julgador (com menor aleatoriedade), dando maior efetividade prática ao contraditório.

Possível, pois, recorrer à Bazerman uma vez mais, em especial o seu alerta para o fato de que, na "comunicação escrita, um texto raramente nos pressiona exigindo atenção, a menos que questione uma compulsão interior" ${ }^{1}$. Em síntese, o autor constata que a palavra pronunciada permite maior atenção por conta da interação face a face, o que, consequentemente, majora as possibilidades de entendimento mútuo ${ }^{52}$.

A leitura e a escrita ocasionam, pois, uma comunicação entre interlocutores que não estão mais na presença um do outro, inexistindo elementos seguros que garantam a devida atenção e, menos ainda, a possibilidade de um alinhamento interacional ${ }^{53}$.

Verifica-se, pois, que são claras as fragilidades que a comunicação escrita possui, podendo ser reduzidas ao se assumir uma comunicação face a face, pautada na oralidade. Nesse sentido, bem esclarece Mauro Cappelletti, ao contrapor a prova testemunhal escrita daquela produzida de forma oral, afirmando que aquela não se caracteriza como uma representação dos fatos, pois "não considera o dado fenomênico em toda sua complexa realidade" 54 .

A assunção da noção de compreensão cênica no processo penal, portanto, com todas essas vantagens em oposição à compreensão textual, causa um primeiro impacto estrutural inegável: uma maior efetividade do contraditório ${ }^{55}$ que, "como regra jurídica constitucional

51 BAZERMAN, Charles. Teoria da ação..., op. cit., p. 136.

52 Nesse sentido: "Na escrita [...], os problemas de atenção e alinhamento são muito maiores do que na interação face a face. Sem a copresença integral, corporificada, os canais de comunicação são mais limitados, a oportunidade de notar resposta e fazer ajustes para manter a atenção e o alinhamento é mais rara e a compulsão por atenção e resposta responsável é mais tênue" (Ibidem, idem).

53 BAZERMAN, Charles. Teoria da ação..., op. cit., p. 137.

54 CAPPELLETTI, Mauro. O valor atual do princípio da oralidade. Revista da Faculdade de Direito da UFRGS, Porto Alegre, v. 21, p. 255-260, mar. 2002, p. 259-260.

55 Sobre a relevância do contraditório no processo penal (princípio basilar), precisas são as palavras de Aury Lopes Jr.: "O contraditório é uma nota característica do processo, uma exigência política, e mais do que isso, se confunde com a própria essência do processo. Como define Rangel Dinamarco - claramente inspirado em Elio Fazzalari -, o conceito moderno de processo 
exteriorizadora do princípio da democracia participativa, representa a efetiva intervenção dos sujeitos processuais no exercício do poder jurisdicional"56; noutras palavras, do contraditório se constata o que Badaró denomina de valor heurístico:

As opiniões contrapostas dos litigantes ampliam os limites do conhecimento do juiz sobre os fatos relevantes para a decisão e diminuem a possibilidade de erros. No processo penal necessariamente haverá o contraditório, em razão da importância dos bens em jogo, pois a solução deste conflito de interesses relevantes exige, sempre, uma decisão oficial e segura, uma vez que a escolha da parte pode ser, e frequentemente o é, errada. ${ }^{57}$

Noutras palavras, a atuação em contraditório deve ser vista como a concretização de uma verdadeira intersubjetividade:

Para usar a linguagem hermenêutico-filosófica, o processo deve depender de um a priori compartilhado; é sempre acusatório, e não inquisitório. Depende do respeito ao contraditório, tudo a partir de uma fundamentação/justificação detalhada - que pode ser denominada de accontability processual. ${ }^{58}$

As características de um efetivo contraditório, portanto, são mais facilmente garantidas através de uma compreensão cênica. Ademais, com essa efetivação trazida pela oralidade ${ }^{59}$, outra circuns-

necessariamente deve envolver o procedimento e o contraditório, sem o que não existe processo" (LOPES JR., Aury. Direito processual..., op. cit., p. 221).

56 SOUZA, Artur César de. Contraditório e revelia: perspectiva crítica dos efeitos da revelia em face da natureza dialética do processo. São Paulo: Revista dos Tribunais, 2003, p. 137.

57 BADARÓ, Gustavo Henrique. Processo Penal. 3. Ed. São Paulo: Revista dos Tribunais, 2015, p. 51-52.

58 STRECK, Lenio Luis e OLIVEIRA, Rafael Tomaz de. O que é isto - as garantias processuais penais? Porto Alegre: Livraria do advogado, 2012, p. 54

59 Aqui vale ressaltar que o doutrinador português Jorge de Figueiredo Dias complementa o princípio do contraditório com o que denomina de princípio da audiência, a partir do qual não bastaria "uma qualquer oportunidade: tem de tratar-se de uma oportunidade, já se disse, efetiva e eficaz, o que supõe em princípio que seja dado ao interessado 1) conhecimento tempestivo do lugar, tempo e objeto do debate, 2) concreta possibilidade de se prepara para a inter- 
tância se evidencia: a importância do papel que as partes possuem na produção probatória, o que garante que o processo penal seja regido por um verdadeiro sistema acusatório.

\subsection{VALORIZAÇÃO DO CONTRADITÓRIO COMO GARANTIA DE UM SISTEMA ACUSATÓRIO}

É sabido que o que diferencia um sistema processual penal como acusatório ou inquisitório reside em que mãos se encontra a gestão da prova: nas do juiz (sistema inquisitório), ou nas das partes (sistema acusatório ${ }^{60}$. É por tal razão que uma maior valorização do contraditório torna o processo mais acusatório, já que a produção probatória ocorrerá numa constante atuação de partes contrapostas. Desta forma, a assunção da compreensão cênica, por valorizar o contraditório a partir da oralidade, acaba por valorizar, também, o sistema acusatório.

Outro ponto que atesta essa afirmação é que, como visto, a compreensão cênica acarreta numa compreensão que é construída (ao longo da sucessão das cenas que constituem o processo), muito diferente do que acontecia no auge dos processos inquisitórios, nos quais a "verdade estava dada ex ante" ${ }^{\prime 1}$. Ademais, essa verdade era vista como uma verdade real ${ }^{62}$ (e ainda o é para alguns, inacreditavelmente), muito diferente de um sistema acusatório, no qual, além de contingencial, a verdade é meramente processual ${ }^{63}$.

venção e 3) efetiva possibilidade de intervir" (DIAS, Jorge Figueiredo. Direito Processual Penal. Coimbra: Coimbra editora, 1974, p. 161, tradução livre).

${ }^{60}$ COUTINHO, Jacinto Nelson de Miranda. Sistema acusatório: cada parte..., op. cit., p. 109.

${ }_{61}$ COUTINHO, Jacinto Nelson de Miranda. Sistema acusatório: cada parte..., op. cit., p. 105.

62 "Excluídas as partes, no processo inquisitório o réu vira um pecador, logo, detentor de uma "verdade" a ser extraída. Mais importante, aparentemente, que o próprio crime, torna-se ele objeto de investigação. É sobre si que recaem as atenções, os esforços do inquisidor. Detentor da "verdade", dela deve dar conta. Eis a razão por que a tortura ganhou a importância que ganhou, e a confissão virou regina probationum" (Ibidem, idem).

${ }_{63}$ "A verdade não é o fim último do processo penal e, sua busca não pode se dar a partir de uma premissa de que os fins justificam os meios. No caso em que uma limitação à descoberta da verdade se justifique para fazer prevalecer outro valor - como o respeito à dignidade humana, à proteção da intimidade, 
Nesse ponto, novamente a compreensão cênica valoriza o princípio (unificador) do dispositivo. Afinal, Hassemer entende que a "ética e a justificação da fase de produção é a 'verdade' do caso; a ética e a justificação da fase de decisão é a 'justiça' da sentença” ${ }^{64}$. Assim:

[...] o conhecimento da verdade material não é o objetivo da fase de produção no Processo Penal. Sua meta é antes a obtenção formalizada da verdade. O Direito Processual Penal coloca diante do juiz, com sua compreensão cênica, uma tarefa que ele absolutamente não pode realizar: buscar a verdade, porém, não a qualquer preço. O preço são os direitos humanos que servem como meio de prova. Estes direitos custam a apuração integral da verdade. $\mathrm{O}$ juiz tem que estar de olhos atentos para produzir um caso que contenha somente uma parte das informações relevantes, porque a outra parte é tabu. O próprio Direito o impede de experimentar tudo que deveria saber para fundamentar sua sentença sobre um caso "verdadeiro". O que ele descobre não é a verdade material, mas a "verdade forense" obtida por caminhos formalizados; e a ela é dirigida a compreensão cênica no Processo Penal..$^{65}$

Não por acaso que essa definição de Hassemer é deveras semelhante com o que concluiu Jacinto Nelson de Miranda Coutinho, ao tratar do sistema acusatório, o qual

não é e nunca foi sinônimo da impunidade, algo, por sinal, por que se reclama tanto do sistema atual. Trata-se isso sim de um sistema que realça o papel das partes a começar por aquele do juiz não só por compatibilizá-los com os ditames constitucionais, mas, sobretudo, em razão de permitir que se caminhe na direção de uma maior democracia processual. ${ }^{66}$

à preservação da imparcialidade do julgador - igualmente ou mais relevante para que se profira uma decisão justa, é de admitir a adoção de regras legais antiepistêmicas, desde que fundamentais para preservar o outro valor do jogo" (BADARÓ, Gustavo Henrique. Processo Penal... op. cit., p. 381). HASSEMER, Winfried. Introdução aos fundamentos..., op. cit., p. 213.

${ }^{65}$ Ibidem, idem. cit., p. 115. 
Essa é a missão da qual se mostra capaz a compreensão cênica: valorizar a oralidade, mas não com fim em si mesmo, e sim visando a majorar a efetividade do contraditório, tornando a produção probatória uma consequência de uma dinâmica (mas organizada) atuação de partes, aumentando a qualidade da atividade e da decisão judiciais, relegando ao processo uma democrática função de regular a sequência de cenas que o constitui.

\section{CONSIDERAÇÕES FINAIS}

Incontestável é o quão radicado está a escrita nas mais diversas etapas do processo penal. Não menos evidente é, pois, os efeitos que uma compreensão textual causa à prática processual. A assunção da oralidade, portanto, ocasiona efeitos outros, facilmente constatáveis com o auxílio, por exemplo, da psicologia cognitiva.

Por certo que apenas transformar práticas escritas, enraizadas pelos operadores do direito, não é uma tarefa fácil, não podendo ser proposta como possuindo um fim em si mesmo. É a noção de compreensão cênica, portanto, que traz um novo entendimento sobre o processo.

Nos estudos de Alfred Lorenzer e, principalmente, na importação destes para o processo penal, realizada por Winfried Hassemer, a oralidade encontra uma porta de entrada para os estudos do Direito processual penal, não apenas mitigando desvantagens próprias da compreensão textual, mas também valorizando, consideravelmente, a atuação da acusação e da defesa em contraditório, o papel do julgador em um processo democrático e, consequentemente, um processo regido por um sistema de matriz acusatória.

Evidentemente, o caminho aqui construído não passa de uma proposta, possuindo o objetivo de ser (mais) uma instigação. Na busca de valorizar os pilares de um processo penal democrático, novas ideias devem sempre ser aceitas para debate.

\section{REFERÊNCIAS}

BADARÓ, Gustavo Henrique. Processo Penal. 3. Ed. São Paulo: Revista dos Tribunais, 2015.

BAZERMAN, Charles. Teoria da ação letrada. Trad.: Milton Camargo Mota, Angela Paiva Dionísio e Judith Hoffnagel. São Paulo: Parábola Editorial, 2015. 
BRUM, Nilo Bairros de. Requisitos retóricos da sentença penal. São Paulo: Revista dos Tribunais, 1980.

BUSATO, Paulo César. Direito penal e ação significativa. 2. Ed. Rio de Janeiro: Lumen Juris, 2010.

BUSATO, Paulo César. Bases de uma Teoria do Delito a Partir da Filosofia da Linguagem. Revista Direito e Liberdade - RDL - ESMARN - v. 14, n. 1, p. 241264, jan./jun. 2012.

CAPPELLETTI, Mauro. O valor atual do princípio da oralidade. Revista da Faculdade de Direito da UFRGS, Porto Alegre, v. 21, p. 255-260, mar. 2002.

CARNELUTTI, Francesco. As Misérias do Processo Penal. 3. Ed. São Paulo: Edijur, 2013.

COUTINHO, J. N. de. M. A lide e o conteúdo do processo penal. Curitiba: Juruá, 1989.

COUTINHO, J. N. de. M. Por que sustentar a democracia do sistema processual penal brasileiro? Disponível em: <http://emporiododireito.com.br/por-quesustentar-a-democracia-do-sistema-processual-penal-brasileiro-por-jacintonelson-de-miranda-coutinho/>. Acesso em 08 mai. 2016.

COUTINHO, Jacinto Nelson de Miranda. Sistema acusatório: cada parte no lugar constitucionalmente demarcado. Revista de Informação Legislativa, v. 183, p. 103-115, 2009.

DIAS, Jorge Figueiredo. Direito Processual Penal. Coimbra: Coimbra editora, 1974. HABERMAS, Jürgen. Consciência moral e agir comunicativo. Trad. Guido A. e Almeida. 2. Ed. Rio de Janeiro: Tempo Brasileiro, 2003.

HASSEMER, Winfried. Introdução aos fundamentos do direito penal. Trad. Pablo Rodrigo Alflen da Silva. Porto Alegre: Sergio Antonio Fabris, 2005.

KAHNEMAN, Daniel. Rápido e devagar: duas formas de pensar. Trad.: Cássio de Arantes Leite. Rio de Janeiro: Objetiva, 2012.

LOPES JR., Aury. Direito processual penal. 11. ed. São Paulo: Saraiva, 2014.

LORENZER, Alfred. El lenguaje destruido y la reconstrucción psicoanalítica Trabajos preliminares para una metateoría del psicoanálisis. Trad. Roberto Bein. Buenos Aires: Amorrortu, 1977.

PAIVA, Caio. Audiência de custódia e o processo penal brasileiro. Florianópolis: Empório do Direito, 2015.

POLI, Camilin Marcie de. O contraditório como elemento essencial do processo. Revista da Academia Brasileira de Direito Constitucional. Curitiba, 2014, vol. 6, n. 11, jul./dez. p. 442-458. 
ROSA, A. M. Guia compacto do processo penal conforme a teoria dos jogos. 2. Ed. Rio de Janeiro: Lumen Juris, 2014.

ROSA, A. M. Narrar histórias no e pelo processo penal, com Jorge Luis Borges. Revista Paradigma, Ribeirão Preto-SP, a. XIX, n. 23, p. 203-216, jan./dez. 2014.

SALLING OLESEN, Henning; WEBER, Kirsten: Socialization, language and scenic understanding: Alfred Lorenzer's contribution to a psycho-societal methodology. In: Historical Social Research, Berlin, v. 38, n. 2, 2013, p. 26-55.

SCHÜNEMANN, Bernd. O juiz como um terceiro manipulado no processo penal? Uma confirmação empírica dos efeitos perseverança e correspondência comportamental. Trad. José Danilo Tavares Lobato. Revista Liberdades, n. 11, p. 30-50, set./dez. 2012.

SOUZA, Artur César de. Contraditório e revelia: perspectiva crítica dos efeitos da revelia em face da natureza dialética do processo. São Paulo: Revista dos Tribunais, 2003.

STRECK, Lenio Luiz e OLIVEIRA, Rafael Tomaz de. O que é isto - garantias processuais penais? Porto Alegre: Livraria do Advogado, 2012.

TIERSMA, Peter. Parchment, Paper, Pixels: Law and the Technologies of Communication. Chicago: University of Chicago Press, 2010. Loyola-LA Legal Studies Paper no. 2010-46. http://dx.doi.org/10.7208/chicago/9780226803074.001.0001

VIANA, Daniel Roepke; ANDRADE, Valdeciliana S. R. Direito e Linguagem: os entraves linguísticos e sua repercussão no texto jurídico processual. In: Revista de Direitos e Garantias Fundamentais, Vitória -ES, n. 5, p. 37-60, jan./jun. 2009.

\section{Informações adicionais e declarações dos autores}

Agradecimentos (acknowledgement): Registro meus agradecimentos a todos os integrantes e participantes do grupo de pesquisa Modernas Tendências do Sistema Criminal (sede em Curitiba/PR) pelo constante incentivo à pesquisa acadêmica e ao debate.

Declaração de conflito de interesses: não há conflitos de interesse na realização das pesquisas expostas e na redação deste artigo.

Declaração de autoria (declaration of authorship): todas e somente as pessoas que atendem os requisitos de autoria deste artigo estão listadas como autores. $\mathrm{O}$ autor se responsabiliza integralmente pelo conteúdo total deste artigo. Declaração de ineditismo e originalidade: assegura-se que o texto aqui publicado não foi divulgado anteriormente em outro meio e que futura republicação somente se realizará com a indicação expressa da referência desta publicação original; não há plágio de terceiros ou autoplágio. 
Dados do processo editorial

(http://www.ibraspp.com.br/revista/index.php/RBDPP/about/editorialPolicies)

- Recebido em: 24/07/2017

- Controle preliminar e verificação de plágio: 24/07/2017

- Avaliação 1: 05/08/2017

- Avaliação 2: 08/08/2017

- Avaliação 3: 09/08/2017

- Decisão editorial preliminar: 16/08/2017

- Retorno rodada de correções: 30/08/2017

- Decisão editorial final: 01/09/2017

\section{Equipe editorial envolvida}

- Editor-chefe: 1 (VGV)

- Editora-associada: 1 (FMB)

- Revisores: 3

\section{COMO CITAR ESSE ARTIGO:}

CARVALHO, Gabriel Rodrigues de. A importância da oralidade no processo penal a partir da noção de compreensão cênica. Revista Brasileira de Direito Processual Penal, Porto Alegre, vol. 3, n. 3, p. 907-928, set./dez. 2017. https://doi.org/10.22197/rbdpp.v3i3.88

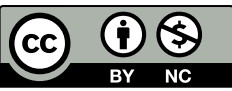

Esta obra está licenciada com uma Licença Creative Commons Atribuição-NãoComercial 4.0 Internacional. 